\title{
Fetal cervical zygapophysial joint with special reference to the associated synovial tissue: a histological study using near-term human fetuses
}

\author{
Kei Kitamura ${ }^{1}$, Shogo Hayashi ${ }^{2}$, Zhe Wu Jin $^{3}$, Masahito Yamamoto ${ }^{4}$, Gen Murakami ${ }^{5}$, \\ José Francisco Rodríguez-Vázquez ${ }^{6}$, Hitoshi Yamamoto ${ }^{1}$ \\ ${ }^{1}$ Department of Histology and Embryology, Tokyo Dental College, Tokyo, ${ }^{2}$ Department of Anatomy, Division of Basic Medical Science, Tokai \\ University School of Medicine, Kanagawa, Japan, ${ }^{3}$ Department of Anatomy, Wuxi School of Medicine, Jiangnan University, Wuxi, China, ${ }^{4}$ Department \\ of Anatomy, Tokyo Dental College, Tokyo, ${ }^{5}$ Division of Internal Medicine, Jikou-kai Clinic of Home Visits, Sapporo, ${ }^{6}$ Department of Anatomy and \\ Embryology, School of Medicine, Complutense University, Madrid, Spain
}

\begin{abstract}
Human fetal cervical vertebrae are characterized by the large zygapophysial joint (ZJ) extending posteriorly. During our recent studies on regional differences in the shape, extent, and surrounding tissue of the fetal ZJ, we incidentally found a cervical-specific structure of synovial tissues. This study aimed to provide a detailed evaluation of the synovial structure using sagittal and horizontal sections of 20 near-term fetuses. The cervical ZJ consistently had a large cavity with multiple recesses at the margins and, especially at the anterior end, the recess interdigitated with or were located close to tree-like tributaries of the veins of the external vertebral plexus. In contrast to the flat and thin synovial cell lining of the recess, the venous tributary had cuboidal endothelial cells. No or few elastic fibers were identified around the ZJ. The venous-synovial complex seems to be a transient morphology at and around birth, and it may play a role in the stabilization of the growing cervical ZJ against frequent spontaneous dislocation reported radiologically in infants. The venous-synovial complex in the cervical region should be lost and replaced by elastic fibers in childhood or adolescence. However, the delayed development of the ligament flavum is also likely to occur in the lumbar ZJ in spite of no evidence of a transient venous-synovial structure. The cuboidal venous endothelium may simply represent the high proliferation rate for the growing complex.
\end{abstract}

Key words: Zygapophysial joint, Ligament, Neck, Human, Fetus

Received October 7, 2020; 1st Revised October 30, 2020; 2nd Revised November 8, 2020; Accepted November 18, 2020

\section{Introduction}

The human zygapophysial joint (ZJ) exhibits regional differences; it has a joint plane between the adjacent articular

\section{Corresponding author:}

Shogo Hayashi (iD

Department of Anatomy, Division of Basic Medical Science, Tokai University School of Medicine, Kanagawa 259-1193, Japan

E-mail:sho5-884@umin.ac.jp processes that extends almost horizontally in the cervical region, frontally in the thoracic region, and sagittally in the lumbar region $[1,2]$. However, radiologic evidence has shown that the cervical ZJ is situated frontally rather than horizontally in infants and children [3]. Therefore, the lower vertebral element is located antero-inferiorly to the upper element at the ZJ. Although many studies have examined the development and growth of fetal cervical vertebrae [4-7], little is known about the shape, extent, and surrounding tissue in the joint cavity in fetuses and children. Furthermore, observations of the ZJ have not been included in imaging 
studies of human fetuses [8-10].

In our recent study of the cervical vertebrae [11-13], we found that the morphology of the fetal cervical ZJ is markedly different than that of the adult cervical ZJ. The joint cavity is very large as it extends posteromedially along the vertebral lamina beyond the articular process. Such posterior extension of the ZJ was not observed during our previous studies on the thoracolumbar vertebrae in mid- and latestage fetuses [11, 14], and it has not been reported in studies on the thoracolumbar vertebrae conducted by other groups $[15,16]$. A disruption while observing the ZJ seems to be the sectional plane; the frontal sections are likely to make discrimination between the lamina and articular process difficult. Therefore, this study aimed examine the morphology of the potentially large cervical ZJ and the associated synovial tissue. We also examined the sagittal and horizontal sections of near-term fetuses.

\section{Materials and Methods}

This study was conducted in accordance with the Declaration of Helsinki 1995 (as revised in 2013) and was approved by the Ethics Committee of Complutense University (B08/374). We examined paraffin-embedded histological sections from 20 near-term fetuses (gestational age, approximately 30-38 weeks; crown-rump length [CRL], 250-315 $\mathrm{mm})$. All fetuses were part of the large collection kept at the Department of Anatomy of Complutense University in Madrid, Spain; they were the results of miscarriages and ectopic pregnancies obtained by the Department of Obstetrics of Complutense University. To demonstrate elastic fibers, most sections were stained with hematoxylin and eosin (H\&E); however, other sections were stained with elastica-Masson (a variation of Masson-Goldner staining) [17, 18]. All sections were prepared with a $50-\mu \mathrm{m}$ or $100-\mu \mathrm{m}$ interval, and sectional planes were sagittal (15 planes) or horizontal (5 planes). Most of the sagittal sections overlapped materials used for our recent studies $[11,12]$. The specimens were not available for immunohistochemistry of the smooth muscle actin, which was necessary for the identification of myofibroblasts, due to the lengthy amount of time spent preserved in an acidic formalin solution. An Eclipse 80 microscope (Nikon, Tokyo, Japan) was used to observe and photograph the specimens.

\section{Results}

Sagittal sections showed that in the cervical ZJ between the third and seventh vertebrae, the joint cavity of the ZJ extended posteriorly along the vertebral lamina to reach the base of the spinous process (Figs. 1-3). The space between the vertebrae appeared narrow in the anterolateral site (i.e., between the articular processes) (Fig. 1A), but it became wider in the posteromedial sites (i.e., between the laminae) (Fig. 1B). Finally, the space was widest between the bases of the spinous processes because the joint cavity extended along the supero-inferior axis in a wide space between the spinous processes (Fig. 1C). The term "joint” was not suitable for the most posterior part because the cavity does not have bone articulation. Figs. $1 \mathrm{~A}$ and $3 \mathrm{~A}$ show the joint cavity between the laminae of the vertebrae and the ZJ between the articular processes of the sixth and seventh vertebrae.

The cervical ZJ consistently had a primitive synovial tissue containing multiple recesses of the joint cavity at the anterior and posterior ends (Figs. 1A, 2A). The deepest or longest recess extended superiorly along the upper adjacent vertebra at the anterior end of the ZJ (Figs. 2C, 3D), whereas the next deepest recess was typically found at the posterior end, where it extended along the lower adjacent vertebra (Figs. 1E, 2E). These deep recesses had a smooth synovial cell lining (Figs. 2C, 3C) and often gave off daughter recesses; the daughter recesses were short and thin. Furthermore, the daughter recess tended to carry rough surfaces because of tiny "capes and gulfs" (Figs. 1D, 2C), and the cuboidal cell lining (Figs. 3C, 4E). In horizontal sections, a deep recess along the upper adjacent vertebra (Fig. 4A, left) indicated the anterior end of the cavity, as seen in sagittal sections. Horizontal sections showed some of the daughter recesses penetrting the thick synovial tissue to reach the lower adjacent vertebral element (Fig. 4B, C). Therefore, the recesses of the joint cavity were likely to create a three-dimensional tree-like configuration in the anterior synovial tissue.

Synovial folds were often seen between the bases of the spinous processes (Fig. 1E) and between the lower cervical vertebrae (Figs. 2E, 3A). A thick periosteum comprising collagen fiber bundles was present at the end of the joint cavity (Fig. 3D, E). No elastic fibers were identified around the joint cavity (Figs. 3C, 4E), with a few exceptions (Fig. 3I); however, the internal elastic lamina of the muscular arteries was welldeveloped in the same specimen (Figs. $3 \mathrm{H}, 4 \mathrm{H}$ ). When compared with the arterial wall, rare elastic fibers around the ZJ 

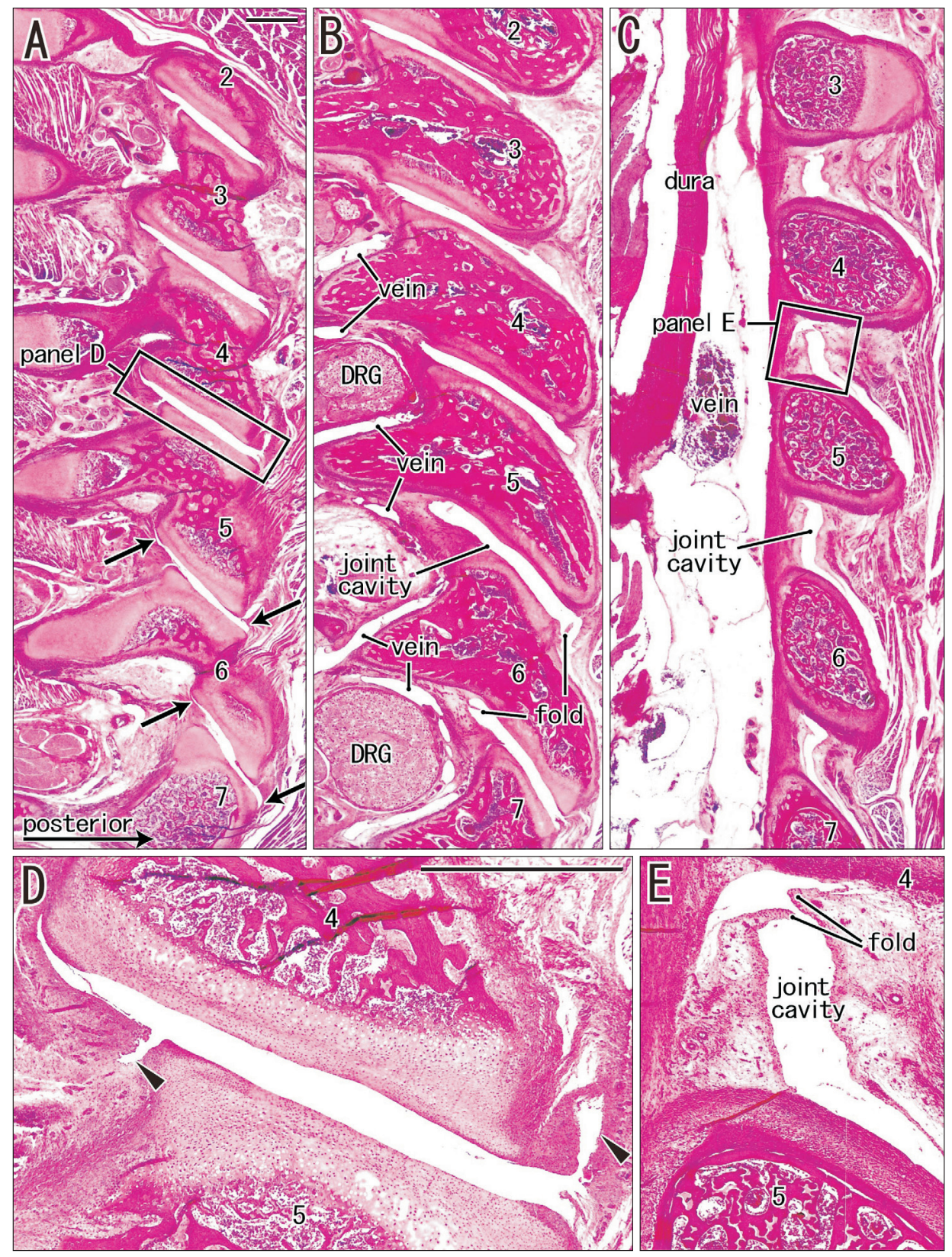

Fig. 1. Sagittal sections of the cervical vertebrae from a fetus with a crown-rump length of $280 \mathrm{~mm}$. Hematoxylin and eosin staining. Joints between the second and seventh vertebrae are included; numbers 2-7 indicate the vertebral level. The joints between the articular processes, laminae, and bases of the spinous processes are shown in (A-C), respectively. (D, E) exhibit higher-magnification views of the square in (A, C), respectively. The joint cavity creates a thin recess at the anterior and posterior ends (arrows in A). Arrowheads in (D) indicate daughter recesses of the cavity between the fourth and fifth vertebrae. $(A-C)$ and $(D, E)$ were prepared at the same magnification, respectively. Scale bars in $(A, D)=1$ $\mathrm{mm}$. DRG, dorsal root ganglion.

were not mature because of the sparse distribution of straight fibers.

Abundant veins or a part of the external vertebral plexus surrounded the ZJ. These veins often had a high, cuboidal endothelium and no or few elastic fibers (Fig. 3F). The venous plexus surrounded the spinal nerve root and ganglion
(Figs. 1B, 2A). Notably, at and near the anterior end of the joint cavity, veins created multiple "recesses" or slit-like tributaries to those inserted deeply in the primitive synovial tissue (Fig. 2B, F); they ramified to create a gulf-like appearance similar to that of the joint cavity recess. A cross-section of the venous recesses was often seen at the anterior of the 


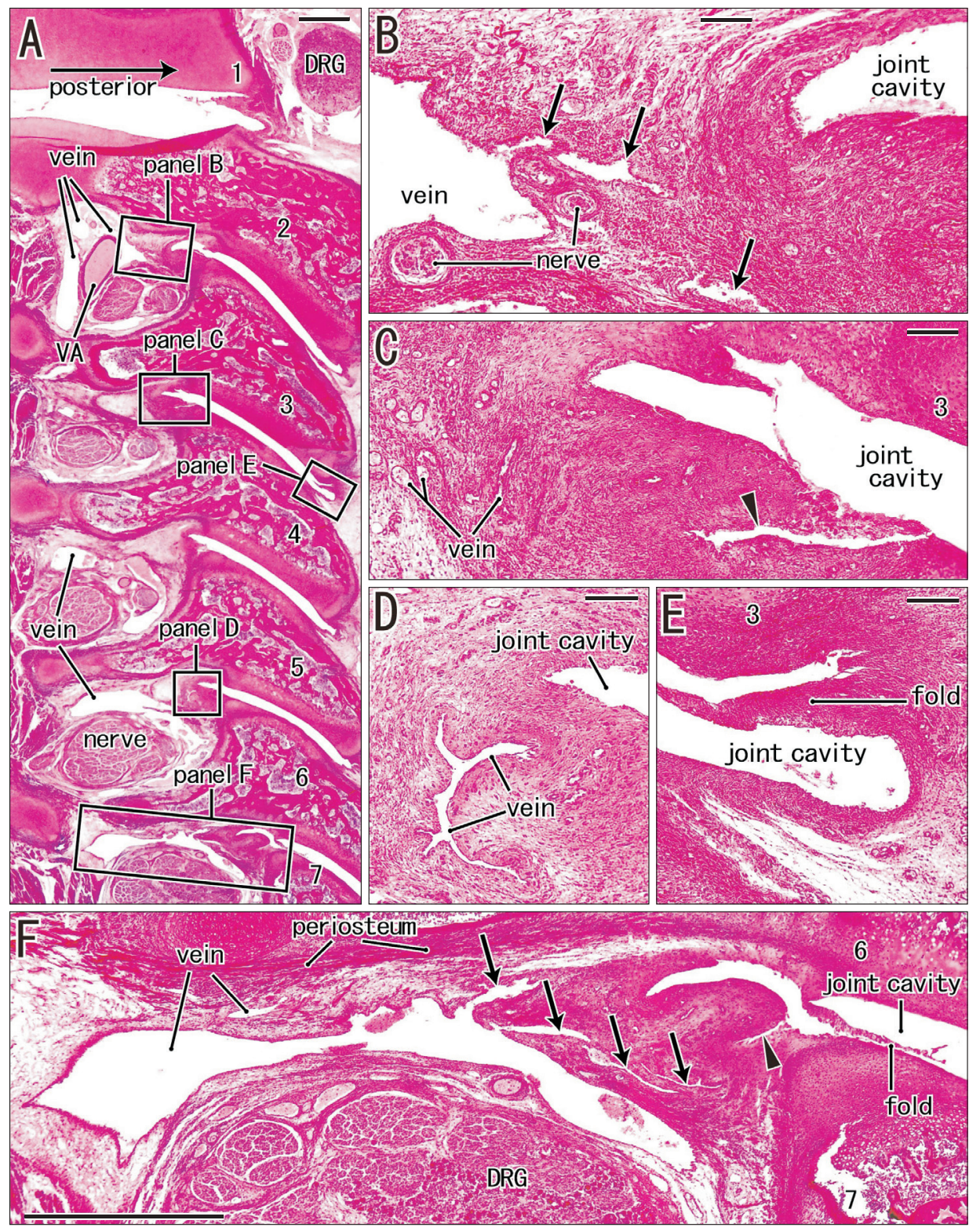

Fig. 2. Sagittal sections of the cervical vertebrae from a fetus with a crown-rump length of $302 \mathrm{~mm}$. Hematoxylin and eosin staining. Joints between the laminae from the first to the seventh vertebrae (A); numbers 1-7 indicate the vertebral level. (B-F) display higher-magnification views of the squares in (A). (B-D) display the anterior end of the joints in levels between the second and third, third and fourth, and fifth and sixth vertebrae, respectively. (B) shows venous tributaries (arrows). (D) shows a cross-section of a vein in the synovial tissue. $€$ shows a synovial fold at the posterior end of the joint between the third and fourth vertebrae. (F) exhibits slit-like or recess-like venous tributaries in the anterior synovial tissue (arrows). Arrowheads in (C, F) indicate a thin daughter recess with a rough surface. Scale bars=1 mm in (A, F); $0.1 \mathrm{~mm}$ in $(\mathrm{B}-\mathrm{E})$. DRG, dorsal root ganglion; VA, vertebral artery.

joint cavity (Fig. 2D). It exhibited an impressive morphology similar to that of the arteriovenous anastomosis or a sphincter of the intestine; however, there was no evidence of the presence of smooth muscles and nerves. At the anterior margins, the joint cavity recesses were located close to, or even interdigitated with, specific venous tributaries. We did not perform three-dimensional reconstruction.

\section{Discussion}

The present study demonstrated a specific synovial tissue containing complicated cavity recesses that were inter- 

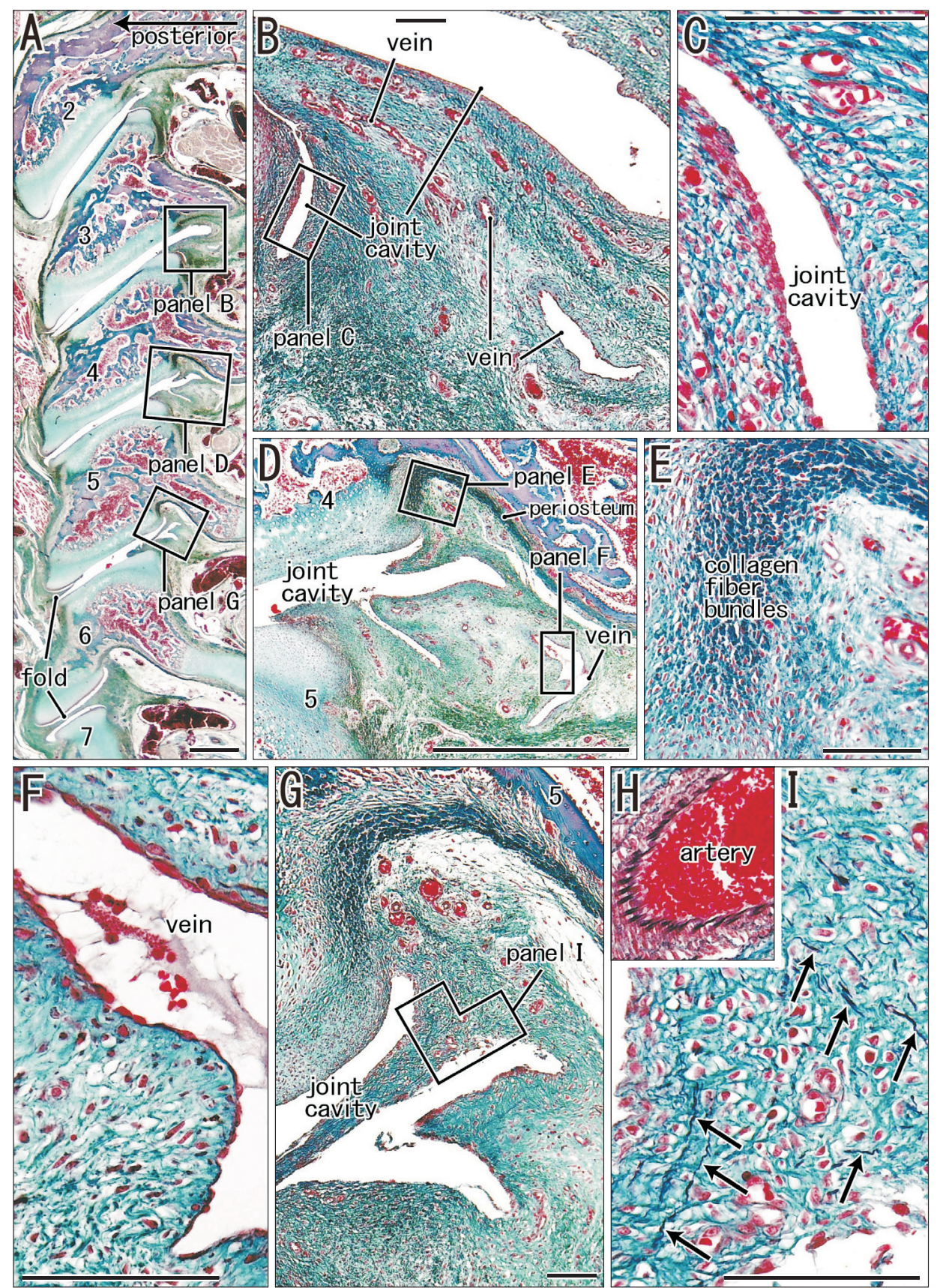

Fig. 3. Sagittal sections of the cervical vertebrae from a fetus with a crown-rump length of $285 \mathrm{~mm}$. Elastica-Masson staining. Joints between the laminae from the second to the sixth vertebrae and a single joint between the articular processes of the sixth and seventh vertebrae (A); numbers 2-7 indicate the vertebral level. (B, D, and G) display higher-magnification views of the squares in (A). (C, E, F, and I) are higher-magnification views of the squares at the anterior end of the joints in $(B, C, D$, and $G$ ), respectively. (B) contains a thin recess of the joint cavity. (C) shows no elastic fibers. (D) exhibits recesses of the joint cavity and a vein at the anterior end of the joint between the fourth and fifth vertebrae. In this area, neither the periosteum (E) nor the vein (F) contains or accompanies elastic fibers. (G) shows recesses of the joint cavity between the fifth and sixth vertebrae; the sixth vertebrae has a few elastic fibers (arrows in I). (H) (same magnification as I) shows the internal elastic lamina of an artery outside of (A). Scale bars=1 $\mathrm{mm}$ in (A, D); $0.1 \mathrm{~mm}$ in (B, C, E-G, and I). DRG, dorsal root ganglion.

digitated with or closely located to venous tributaries of the external vertebral plexus (Fig. 5). According to our previous study, it had been specifically found in the subaxial cervi- cal region [13]. The venous-synovial complex was usually seen at the anterior end of the cervical ZJ, and it seemed to be a transient morphology in late-stage fetuses and, pos- 

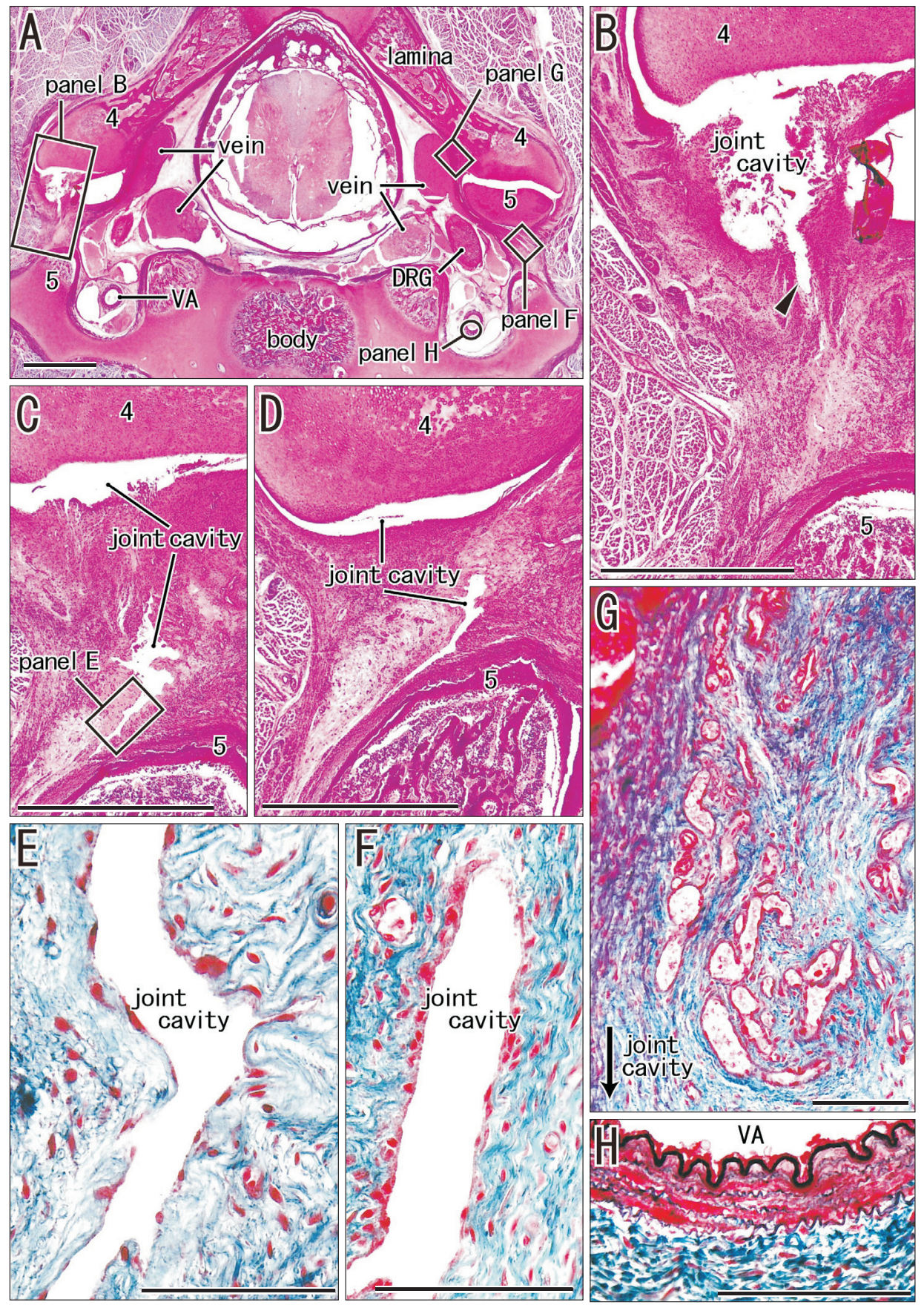

Fig. 4. Horizontal sections of the mid-cervical vertebrae from a fetus with a crown-rump length of $310 \mathrm{~mm}$. Hematoxylin and eosin staining (AD) and elastica-Masson staining $(\mathrm{E}-\mathrm{H})$. A shows the topographical anatomy of a joint between the fourth and fifth vertebrae (4, 5); at the joint (right), the lower vertebral element is located anterior to the upper adjacent vertebra. (B) is a higher-magnification view of a joint on the left side of (A). (B, C) exhibit planes 0.2 and $0.4 \mathrm{~mm}$, respectively, below (A). A recess of the joint cavity originates in (B) (arrowhead) and extends inferoanteriorly in $(B, C)$. (E) shows a higher-magnification view of the square in $(C)$. (F, G) are higher-magnification views of squares in (A). There are no evident elastic fibers around the recesses of the joint cavity $(\mathrm{E}, \mathrm{F}) .(\mathrm{G})$ displays a venous plexus in synovial tissue on the medial side of the joint. $(\mathrm{H})$ exhibits highly wavy elastic fibers in a wall of the vertebral artery (VA). The thick bundle just below the VA corresponds to the internal lamina, whereas the other thin bundles are embedded in the future smooth muscle layer. Scale bars $=2 \mathrm{~mm}$ in $(\mathrm{A}) ; 1 \mathrm{~mm}$ in $(\mathrm{B}-\mathrm{D}) ; 0.1 \mathrm{~mm}$ in $(\mathrm{E}-$ H). DRG, dorsal root ganglion; VA, vertebral artery. 


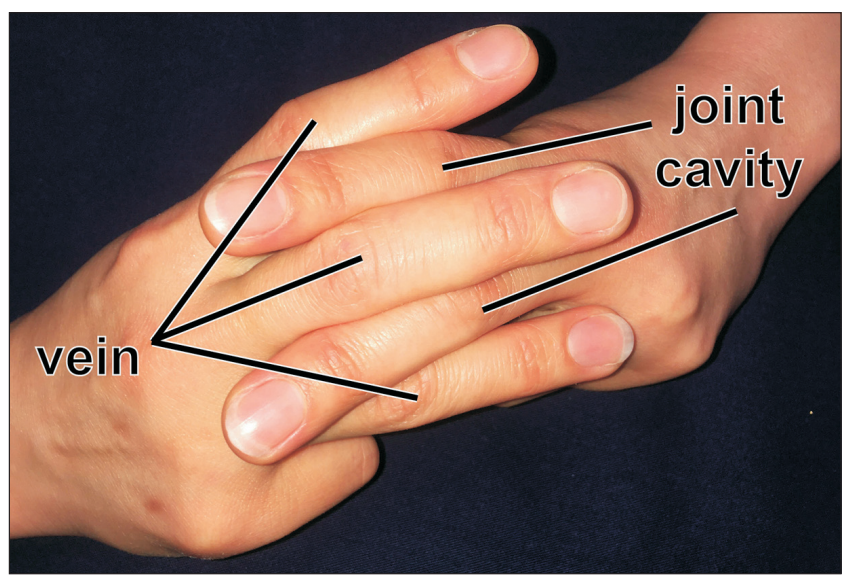

Fig. 5. Hand-finger model showing the topographical relationship between the venous tributaries and joint cavity of the cervical zygapophysial joints. Venous tributaries (vein) intercalate with recesses of the joint cavity, especially at the anterior margin of the latter.

sibly, in infants. Based on radiologic evidence, Cattell and Filtzer [3] reported frequent anterior dislocation of the cervical vertebrae in infants and children. The venous-synovial complex might have a critical role in the stabilization of the ZJ in infants until establishment of the ligamentum flavum. Blood in the synovial tributaries of veins likely pushed the joint cavity in the posterior direction. A cross-section of a specific vein in the synovial tissue exhibited an appearance similar to that of arteriovenous anastomosis, which should contain smooth muscles, elastic fibers, arterial branches, and nerves [19-21]. However, we did not find elastic fibers or arterial branches around the synovial vein. The spinal nerve root and ganglion were surrounded by the vertebral venous plexus and, therein, the veins were likely to reduce mechanical stress from the joint movement. Likewise, to avoid injury by the suggested dislocation in infants, a complex of venous tributaries seemed to provide a cushion to the deep recess.

A capsule of the ZJ contained abundant elastic fibers in adults [22]. In the head and neck, until 30 weeks of gestation, elastic fibers appeared in the larynx, pharynx, middle ear, pharyngotympanic tube, and auricle [23], as well as in the ligamentum nuchae behind the cervical vertebrae [11]. To create the ligamentum flavum, elastic fibers should occupy later posterior large parts of the ZJ between the cervical vertebral laminae. Therefore, replacement of the joint cavity by elastic fibers most likely occurs between the cervical laminae in childhood or adolescence. We have previously reported analogies of such a replacement by elastic fibers in aged cricothyroid joints [24] and fetal incudopetrosal joints [25, 26].
The cricothyroid joint is often closed by elastic fibers with aging, whereas the incudopetrosal joint between the incus and petrosal part of the temporal bone changes into the posterior ligament of incus, possibly after birth. These two joints should resist against vibration because collagen fibers are not suitable for the maintenance of joint stability under vibration [27]. Therefore, instead of vibration, a specific "cue" seems necessary for the suggested delayed synthesis of elastic fibers in the cervical ligamentum flavum. Postnatal growth of the uncinated process and Luschka joint stabilizes the anterior part of the cervical vertebral column [28] and it seemed to rescue spontaneous dislocation of the cervical ZJ. Accordingly, the venous-synovial complex seemed to become unnecessary.

Unfortunately, we were not able to identify myofibroblasts, which have a critical role in the production and degeneration of elastic fibers in the ligamentum flavum, near and around the large cervical ZJ using immunohistochemistry [29]. No or few elastic fibers around the ZJ near term suggested that ligament development occurs after birth. In the adult ligament flavum, there are several pathologies such as hypertrophy [30] and disorganization and replacement by collagen fibers [31]. With these pathologies, transforming growth factor-beta production by the vascular endothelium regulates the synthesis of elastic fibers by fibroblasts. Conversely, mechanical stresses induce the production of angiopoietin-like protein by fibroblasts; this protein activates transforming growth factor-beta signaling, which results in ligament hypertrophy and/or degeneration [32]. Nevertheless, to assist the vertebral column extension, the ligament flavum exists not only in the cervical region [2] but also in the lumbar region $[33,34]$. Therefore, the cervical-specific venous-synovial complex seemed not to play a role of the mother substrate and/or stimulator of the elastic fiber production.

A cuboidal cell lining was seen in veins as well as synovial recesses in the complex: such synovial cells had been described as cytoplasm-rich cells in fetal synovial tissues of the knee and elbow, but the role is unknown [35-37]. In contrast, as a site of the lymphocyte recruitment, a cuboidal endothelial lining is known well in the postcapillary high endothelial venule of lymph nodes [2]. However, in both of the synovium and veins, the present cuboidal cell lining might simply represent a high activity of proliferation for the growing venoussynovial complex. 


\section{ORCID}

Kei Kitamura: https://orcid.org/0000-0003-3335-1440

Shogo Hayashi: https://orcid.org/0000-0003-0302-7658

Zhe Wu Jin: https://orcid.org/0000-0002-6789-2977

Masahito Yamamoto:

https://orcid.org/0000-0001-9683-6678

Gen Murakami: https://orcid.org/0000-0001-7181-5475

José Francisco Rodríguez-Vázquez:

https://orcid.org/0000-0001-5423-4492

Hitoshi Yamamoto:

https://orcid.org/0000-0002-4181-6271

\section{Author Contributions}

Conceptualization: KK, MY, HY. Data acquisition: KK, ZWJ, MY, JFRV. Data analysis or interpretation: KK, SH, GM, JFRV. Drafting of the manuscript: KK, SH, GM. Critical revision of the manuscript: ZWJ, MY, JFRV, HY. Approval of the final version of the manuscript: all authors.

\section{Conflicts of Interest}

No potential conflict of interest relevant to this article was reported.

\section{References}

1. Bogduk N. Functional anatomy of the spine. Handb Clin Neurol 2016;136:675-88.

2. Gray H, Williams PL. Gray's anatomy. 38th ed. New York: Livingstone; 1995. p. 516-22, 1431-6.

3. Cattell HS, Filtzer DL. Pseudosubluxation and other normal variations in the cervical spine in children. A study of one hundred and sixty children. J Bone Joint Surg Am 1965;47:1295309.

4. Castellana C, Kósa F. Morphology of the cervical vertebrae in the fetal-neonatal human skeleton. J Anat 1999;194(Pt 1):147-52.

5. Müller F, O'Rahilly R. Segmentation in staged human embryos: the occipitocervical region revisited. J Anat 2003;203:297-315.

6. O'Rahilly R, Muller F, Meyer DB. The human vertebral column at the end of the embryonic period proper. 1 . The column as a whole. J Anat 1980;131(Pt 3):565-75.

7. San Román P, Palma JC, Oteo MD, Nevado E. Skeletal maturation determined by cervical vertebrae development. Eur J Orthod 2002;24:303-11.

8. Bagnall KM, Harris PF, Jones PR. A radiographic study of the growth in width of the human fetal vertebral column. Anat Rec 1982;204:265-70.
9. Cheng PJ, Huang SY, Shaw SW, Chueh HY, Soong YK. Evaluation of fetal spine biometry between 11 and 14 weeks of gestation. Ultrasound Med Biol 2010;36:1060-5.

10. Glenn OA, Barkovich AJ. Magnetic resonance imaging of the fetal brain and spine: an increasingly important tool in prenatal diagnosis, part 1. AJNR Am J Neuroradiol 2006;27:1604-11.

11. Kitamura K, Cho KH, Yamamoto M, Ishii M, Murakami G, Rodríguez-Vázquez JF, Abe SI. Suboccipital myodural bridges revisited: application to cervicogenic headaches. Clin Anat 2019;32:914-28.

12. Sakanaka K, Yamamoto M, Hirouchi H, Kim JH, Murakami G, Rodríguez Vázquez JF, Abe SI. A temporary disc-like structure at the median atlanto-axial joint in human fetuses. Anat Cell Biol 2019;52:436-42.

13. Kitamura K, Kim JH, Cho KH, Murakami G, RodríguezVázquez JF, Yamamoto H. Regional differences in zygapophysial joint cavities: a histological study of human fetuses. Anat Rec (Hoboken) 2020 Oct 9 [Epub]. https://doi.org/10.1002/ ar.24532.

14. Cho KH, Jin ZW, Abe H, Shibata S, Murakami G, RodríguezVázquez JF. Neural-dural transition at the thoracic and lumbar spinal nerve roots: a histological study of human late-stage fetuses. Biomed Res Int 2016;2016:8163519.

15. Khorooshi MH, Fischer Hansen B, Keeling J, Nolting D, Kjaer I. Prenatal localization of the dorsal root ganglion in different segments of the normal human vertebral column. Spine (Phila Pa 1976) 2001;26:1-5.

16. O'Rahilly R, Müller F, Meyer DB. The human vertebral column at the end of the embryonic period proper. 3. The thoracicolumbar region. J Anat 1990;168:81-93.

17. Hayashi T, Kumasaka T, Mitani K, Yao T, Suda K, Seyama K. Loss of heterozygosity on tuberous sclerosis complex genes in multifocal micronodular pneumocyte hyperplasia. Mod Pathol 2010;23:1251-60.

18. Motohashi O, Suzuki M, Shida N, Umezawa K, Ohtoh T, Sakurai Y, Yoshimoto T. Subarachnoid haemorrhage induced proliferation of leptomeningeal cells and deposition of extracellular matrices in the arachnoid granulations and subarachnoid space. Immunhistochemical study. Acta Neurochir (Wien) 1995;136:88-91.

19. Barbolini G, Tischendorf F, Curri SB. Histology, histochemistry, and function of the human digital arteriovenous anastomoses (Hoyer-Grosser's organs, Masson's glomera). I. The possible relationship with Pacinian corpuscles. Microvasc Res 1971;3:142-53.

20. Jin ZW, Cho KH, Jang HS, Murakami G, Rodríguez-Vázquez JF, Yamamoto M, Abe SI. Coccygeal body revisited: an immunohistochemical study using donated elderly cadavers. Anat Rec (Hoboken) 2017;300:1826-37.

21. Hurley HJ Jr, Mescon H, Moretti G. The anatomy and histochemistry of the arteriovenous anastomosis in human digital skin. J Invest Dermatol 1956;27:133-45.

22. Yamashita T, Minaki Y, Ozaktay AC, Cavanaugh JM, King AI. A morphological study of the fibrous capsule of the human 
lumbar facet joint. Spine (Phila Pa 1976) 1996;21:538-43.

23. Kinoshita H, Umezawa T, Omine Y, Kasahara M, RodríguezVázquez JF, Murakami G, Abe S. Distribution of elastic fibers in the head and neck: a histological study using late-stage human fetuses. Anat Cell Biol 2013;46:39-48.

24. Kawamoto A, Honkura Y, Suzuki R, Abe H, Abe S, Murakami G, Katori Y. Cricothyroid articulation in elderly Japanese with special reference to morphology of the synovial and capsular tissues. J Voice 2016;30:538-48.

25. Rodríguez-Vázquez JF, Yamamoto M, Kim JH, Jin ZW, Katori Y, Murakami G. The incudopetrosal joint of the human middle ear: a transient morphology in fetuses. J Anat 2020;237:176-87.

26. Takanashi Y, Shibata S, Katori Y, Murakami G, Abe S, Rodríguez-Vázquez JF, Kawase T. Fetal development of the elasticfiber-mediated enthesis in the human middle ear. Ann Anat 2013;195:441-8.

27. Kawase T, Shibata S, Katori Y, Ohtsuka A, Murakami G, Fujimiya M. Elastic fiber-mediated enthesis in the human middle ear. J Anat 2012;221:331-40.

28. Clausen JD, Goel VK, Traynelis VC, Scifert J. Uncinate processes and Luschka joints influence the biomechanics of the cervical spine: quantification using a finite element model of the C5-C6 segment. J Orthop Res 1997;15:342-7.

29. Hur JW, Bae T, Ye S, Kim JH, Lee S, Kim K, Lee SH, Kim JS, Lee JB, Cho TH, Park JY, Hur JK. Myofibroblast in the ligamentum flavum hypertrophic activity. Eur Spine J 2017;26:2021-30.

30. Sairyo K, Biyani A, Goel V, Leaman D, Booth R Jr, Thomas J, Gehling D, Vishnubhotla L, Long R, Ebraheim N. Pathomechanism of ligamentum flavum hypertrophy: a multidisciplinary investigation based on clinical, biomechanical, histologic, and biologic assessments. Spine (Phila Pa 1976) 2005;30:2649-56.

31. Mwaka ES, Yayama T, Uchida K, Kobayashi S, Kokubo Y, Nakajima H, Sato R, Orwotho NT, Baba H. Calcium pyrophosphate dehydrate crystal deposition in the ligamentum flavum of the cervical spine: histopathological and immunohistochemical findings. Clin Exp Rheumatol 2009;27:430-8.

32. Nakamura T, Okada T, Endo M, Kadomatsu T, Taniwaki T, Sei A, Odagiri H, Masuda T, Fujimoto T, Nakamura T, Oike Y, Mizuta H. Angiopoietin-like protein 2 induced by mechanical stress accelerates degeneration and hypertrophy of the ligamentum flavum in lumbar spinal canal stenosis. PLoS One 2014;9:e85542.

33. Viejo-Fuertes D, Liguoro D, Rivel J, Midy D, Guerin J. Morphologic and histologic study of the ligamentum flavum in the thoraco-lumbar region. Surg Radiol Anat 1998;20:171-6.

34. Okuda T, Baba I, Fujimoto Y, Tanaka N, Sumida T, Manabe H, Hayashi Y, Ochi M. The pathology of ligamentum flavum in degenerative lumbar disease. Spine (Phila Pa 1976) 2004;29:1689-97.

35. McDermott LJ. Development of the human knee joint. Arch Surg 1943;46:705-19.

36. Gray DJ, Gardner E. Prenatal development of the human knee and superior tibiofibular joints. Am J Anat 1950;86:235-87.

37. Isogai S, Murakami G, Wada T, Ishii S. Which morphologies of synovial folds result from degeneration and/or aging of the radiohumeral joint: an anatomic study with cadavers and embryos. J Shoulder Elbow Surg 2001;10:169-81. 